\title{
Analysis of Organizational Commitments Based on Lecturer Characteristics
}

\author{
Bahdin Nur Tanjung ${ }^{1}$, Elfrianto ${ }^{1}$ \\ ${ }^{1}$ University of Muhammadiyah Sumatera Utara (UMSU), Medan, Indonesia \\ bahdinnur@umsu.ac.id
}

\begin{abstract}
This study aims to find out: 1) Differences in lecturer organizational commitment based on gender on permanent lecturers at University of Muhammadiyah Sumatera Utara, 2). Differences in lecturer organizational commitment based on experience or period of work for permanent lecturers at University of Muhammadiyah Sumatera Utara 3). Differences in lecturer organizational commitment based on interaction between gender and experience or period of work for permanent lecturers at University of Muhammadiyah Sumatera Utara. The study used a comparative descriptive method that is to analyze organizational commitments that are bound variables based on two sample groups namely the characteristics of lecturers of both gender and experience. Data was collected from a sample of as many as 40 male lecturers and 38 female lecturers using likert scale model quesionaries. The selected research design is a factorial design that is $2 \times 2$. A $2 \times 2$ factorial design using ANAVA analysis. His research results showed that gender, experience and interaction co-determined commitment to the organization.
\end{abstract}

Keywords : organizational commitment; lecturer characteristics

\section{Introduction}

University of Muhammadiyah Sumatera Utara (UMSU) Medan is one of the private highemployment which has many students, which is to reach more than 24 thousand people.To organize a lecture process for such students is not an easy one, hence a correct management is needed for the lecture process to go well. In this case the lecturer holds an important role in university operasonals in addition to the clerk's power as the executor of administrative services.

The results of the preliminary study show still the existence of lecturer working but do not show a high commitment to the university. It is visible from their unoptimum performance, less persistent efforts and declining work spirits. The lecturer's constancy is also not entirely high so in implementing the work is impressed to be stuck as is generally a slow, routine workwork and far from a feel or competitive climate. If this problem is continually left to take place it will be able to bring about a negative impact that is the decrease in the performance and productivity of the lecturer's work. The organization's commitment must therefore be increased in order for the lecturer to carry out his work by remaining vigorous and tenacious and persistent in an effort to improve its performance. To that end it takes efforts to find factors that affect the organization's commitment in order to be kept up to no decline in order for the organization of education at the university to be smooth and effective.

In order to avoid discussion bias, research conducted is limited only to organizational commitments based on lecturer characteristics, that is, based on the gender of the lecturer, the lecturer's work experience. For the lecturer experience is distinguished in two groups that are less than 5 years and 5 years or so.The intended lecturer is the permanent lecturer of University of Muhammadiyah Sumatera Utara.

To further clarify the problem based on the limitations of the above problem then the principal problems of the study are formulated as follows. 1). Is there any difference in the commitment of the lecturer organization based on gender on the regular lecturer of University of Muhammadiyah Sumatera Utara.? 2). Is there any difference in lecturer organizational 
commitment based on experience or period of work on the permanent lecturer of University of Muhammadiyah Sumatera Utara.3). Is there any difference in lecturer organizational commitment based on interaction between gender and experience or tenure on the permanent lecturer of University of Muhammadiyah Sumatera Utara?.

The research was implemented with the aim of knowing and analyzing how leadership applied at the University of Muhammadiyah Sumatera Utara . In addition research also aims to know employees' perceptions of the motivations it receives, as well as knowing the organizational commitments of the employees. More specifically the research objectives can be stated as follows.

\subsection{Organizational commitment}

\section{Review of Literature}

Organizational commitment has a diverse sense though on a basis not different from the various deficiencies. The commitment derives from the Latin word "Committer" meaning to combine, unify, trust and work on it. The commitment is also interpreted as "psychological binding" with an organization (Koommoo \& Penny (2008). It is further explained that commitment is also an attitude that leads or mediates one's real response or one's behavioral intentions. Whereas Robbins (2001) mentions commitment as a level where one identifies with the organization and its purpose of conforming and desires to maintain its membership in the organization. In line with that, Durham et al, (2006) defenifies commitment as a force that binds a person to an action that has relevance to one or more goals. It can thus be concluded that commitment is not merely as a member, but rather that one will be willing to strive and do at a high degree for the interests of the organization, in order to facilitate achieving the goals of the organization where he joins it.

Commitment can be divided into three levels, namely commitment to the task and commitment to the organization. Job Commitment is a commitment related to work activities, which is influenced by personal characteristics such as conformity with work and task characteristics such as variations in skills, job identity, level job interests, autonomy, and job feedback (Daft, Robert, 2005). Some studies conclude that work motivation is formed by three conditions, namely if workers feel their work means, workers feel responsible for their work, and workers understand the results of their work.

In contrast to commitment to tasks, commitment to a career (Career Commitment) is a commitment to a career of having wider and stronger coverage compared to commitment to a task or job. This commitment is more in touch with a career field than a set of activities and is a stage where the requirements of a particular job meet the aspirations of an individual's career. It is possible that individuals who have a high commitment to a career will leave the organization to achieve even higher opportunities. Therefore organizational commitments have a wider meaning and coverage compared to commitments to tasks.

Organizational commitment (Organizational Commitment), is the highest level of commitment (Collquit,2009).Porter and Steers define organizational commitment as relative degrees of attachment from individuals to their organizations. Organizational commitments include loyal attitudes of organizational members or continuously showing organizational concern and survival. This means to a degree to what extent a person sits with an organization and intends to maintain membership in the organization (George \& Jones, 2002). This commitment includes three attitudes, namely: (1) feelings of identification with the organization's mission, (2) a sense of involvement in the task - organizational tasks, (3) a sense 
of loyalty and love for the organization as a place to live and work, regardless of the benefits and mission of the organization.

Commitment underlies the spirit of someone towards the organization in which he lives. This commitment will also determine how much sensitivity, love and struggle someone has towards the organization. Therefore the commitment of an employee to the organization where he works is a behavioral dimension that can be used to measure and evaluate the strength of the employee in maintaining and carrying out the duties of his obligations to the organization. Commitment is seen as a value orientation towards organizations that shows individuals thinking and prioritizing work and organization (McShane, et.al, 2008). Individuals will try to give all their efforts in order to help the organization achieve its goals.

Many definitions of organizational commitment. Mathis and Jackson (2001) state the organization's commitment as a degree or level of trust and one's acceptance of the organization's purpose of having a desire to remain within the organization reflected in the absence statistics as well as out into the workforce/turnover.

Another opinion expressed by Robbins (2001) which defines organizational commitment as a situation where an employee sided with a particular organization and its objectives, and intends to maintain membership in the organization. This alignment is caused by high work involvement in the work which at the same time sided with the organization where he worked. Similarly, Mowday, Steers and Porter (Sopiah, 2008) define organizational commitment as the relative power of one's alignments and involvement with an organization. The form of commitment that appears in employees is not only passive loyalty but also involves active relationships with organizations that have the goal of providing everything effort for the success of the organization in question. It is this that distinguishes commitment with attachment (attachment). Attachment is a low form of commitment, whereby individuals in joining and helping organizations depend heavily on the existence of accepted (feedback) rewards.

Referring to the definition of commitment commitment to the organization reflects three main dimensions, namely commitment is seen to reflect the affective orientation of the organization, consideration of losses if leaving the organization, and moral burden to continue to be in the organization.Meyer and Allen (1991) formulate three dimensions of commitment in organization, namely: affective, continuance, and normative. These three things are more accurately expressed as components or dimensions of organizational commitment, rather than the types of organizational commitment. This is due to the relationship between members of the organization and the organization reflecting the differences in the third degree of the dimension. someone who is committed to employee loyalty to their organization, and is an ongoing process where organizational participants express concern for the organization and ongoing success. This is in line with several other opinions. Organizational commitment has three main components (Meyer, Allen and Smith in Sopiah, 2008), namely:

1) Affective commitment, which is a commitment that occurs when someone wants to be part of an organization because of an emotional bond. Affective commitment is related to the emotional relationship of members to their organization, identification with the organization, and involvement of members with activities in the organization. Members of organizations with high affective commitment will continue to be members of the organization because they really have a desire for it.

2) Continuance commitment, which is a commitment that arises when someone wants to stay in an organization because it requires other benefits, or because the employee does not find another job. Continuance commitment is related to the awareness of organizational 
members to suffer losses if they leave the organization. Members of organizations with high continuance commitment will continue to be members of the organization because they have the need to become members of the organization.

3) Normative commitment, namely commitment that arises from values in a person. Someone will survive as a member of the organization because of the awareness that commitment to the organization is something that should be done. Normative commitment describes the feeling of attachment to continue to be in the organization. Members of the organization with high normative commitment will continue to be members of the organization because they feel they must be within the organization.

There are several studies on affective commitment. Based on these studies three major categories were obtained. The three categories were: Organizational Characteristics, Individual Characteristics and Work Experience. Organizational characteristics that influence the development of affective commitment are decentralized systems, namely the existence of fair organizational policies, and ways to convey organizational policies to individuals. There have been several studies stating that gender affects affective commitment, but others state it is not. In addition age also affects the process of forming affective commitment, although depending on some individual conditions themselves, organizational tenure, marriage status, education level, the need for achievement, work ethic, and individual perceptions regarding its competence.

The experience of individual work affects the process of forming affective commitments among other things is Job scope, namely some characteristics that show individual satisfaction and motivation. It includes challenges in work, the degree of individual autonomy, and the variation of abilities that individuals use.Besides it is the role of individuals in the organization and its relationship with superiors. individual organizational experience is derived from the services that does in the church and also his interactions with other church members such as his leaders. Continuance commitment can develop because of various actions or events that can increase losses if leaving the organization, and some actions or events occur due to investments and alternatives. In addition, the process of consideration can also affect individuals. Investments include something valuable, including time, effort or money, which individuals must release if they leave the organization while alternatives are likely to enter other organizations. In this case the role of the consideration process applies when individuals achieve investment awareness and alternatives and their impact on themselves. Normative commitment to organizations can develop from a number of pressures felt by individuals during the process of socialization and during socialization when new individuals enter the organization. Normative commitment develops because organizations provide something valuable to individuals. While psychological contracts are the beliefs of each party that each reciprocal will give.

Further stated that each component has a different basis. Someone who has a high affective component still joins the organization because of the desire to remain a member of the organization. Meanwhile someone with a high continuance component will choose to stay in the organization because it requires an organization for its life. Whereas someone who has a high normative component will remain a member of the organization because they have to do it. Steers (Rosidah, 2008) identify the factors that influence organizational commitment based on three characteristics, namely:

1) Personal characteristics of workers, including their tenure in the organization and variations in their needs, such as the need for achievement. 
2) Characteristics of work, including the identity of the task and the opportunity to interact with colleagues in the organization.

3) Work experience, including the reliability of the organization in the past and the way other members discuss their feelings about the organization.

To increase the commitment of organizational workers, they need to meet the expectations of workers, both the desire to be respected for their existence in the organization, and the expectation that they are given the opportunity to develop achievements by giving workers responsibilities about their work. Serser (in Sopiah, 2008) factors, namely:

1) Trust and strong acceptance of the goals and values of the organization.

2) Willingness to work towards achieving organizational interests

3) A strong desire to maintain organizational membership.

Commitment in organizations has many benefits and is very urgenous in each organization.Individuals that actually show high commitment to organizations have a much greater possibility of showing high levels of participation in organizations. Moreover, organizational commitments will increase a stronger desire to stay working on organizations and continue to make donations to goal achievement. Likewise, efforts involve themselves in their work, as the work is a key mechanism and individual channel to make its donation to the attainment of the organization's goals. The commitment to the organization has negative relationships, both with job care and with the level of exit of the members.

There are two approaches in formulating definitions and developments in organizational commitment. Commitments can appear in various forms, that are differences in relationships between members of the organization and other entities (one of them is the organization itself). In addition, efforts to separate between various entities in which individuals develop have commitment is also another approach. Before the advent of both approaches, there was another approach that first appeared and was longer used, namely distinction based on attitudinal commitment or approach based on attitude and behavioral commitment). This distinction has implications not only to the definition and measurement of commitment, but also the approaches used in various developmental studies and commitment consequences. Attitudinal commitment focuses on the process of how a person starts thinking about his relationship in an organization or determines his attitude towards an organization while behavioral commitment relates to a process in which individuals feel bound to certain organizations and how they deal with every problem faced by them. This has a distinctive impact on each individual on his commitment to be loyal and loyal and committed to the organization where they are members.

\subsection{Lecturer Characteristics}

Biologically both males and females have a marked difference. The difference is apparent in the reproductive tools. The biological differences of males and females are due to the presence of different hormones that result in different treatments of both males and females. In addition to biological factors, psychological factors are also an influential factor towards male and female differences.

Psychological factors for both males and females have impacts also related to intelegence, attention, interest, talent, motivation, maturity, and readiness. Biological anatomical differences and chemical composition in the body by a number of scientists are also considered influential on emotional development and intellectual capacity. Women are generally better at memory and men are better at logical thinking. Women are more interested in practically congruent life problems, whereas men are more interested in abstract facets 
(Kartono, 1989). Psychological factors are also influential in learning achievements. Usman and Setiawati (2001) explain several factors that affect learning achievement, namely Internal and external factors. Internal factors consist of physical, psychological, physical maturity and psychic factors. External factors consist of social, cultural factors such as customs, science, technology, arts, physical environment, and spiritual as well as religious environmental factors (Heriyanto, 2012).

Physiological and psychological factors can lead to differentiation of learning achievements. The presence of psychological factors in learning, will provide sufficient fair share Important. Psychological factors will constantly provide grounding and ease in an effort to achieve the goal of learning optimally. Achievement, performance, affiliation, and power are also influenced by psychological factors.Achievement is a strong motivation in each individual to needs, needs gained from culture and environment. The difference between male and female will shape culture and become a different environment, giving rise to the differences in her commitment to the organizational group that she has become her shelter.

Work experience is the process of forming a person over knowledge or skills about the method of a job because of that involvement in the execution of a job task. Work experience is a measure of the length of time or time a person has taken can understand the task-duty of a job and has carried out well.

In addition the work experience is also interpreted as knowledge or skill that one has known and mastered as a result of deeds or work that has been done for some time (Foster, 2001). From the description it can be concluded, that work experience is the level of mastery of one's knowledge as well as skill in his or her work that can be measured from work and from the level of knowledge as well as skills he or she has

Measurement of work experience as a means to analyze and encourage efficiency in the implementation of work tasks. Work experience can also be seen from the behavior attitude of the work, such as (1) Steady and smooth movement An experienced person will make steady movements in work without any doubts. (2) The movement is rhythmic where the habit of doing daily work is created. (3) Faster to respond to signs, such as there will be work accidents. (4) It can suspect that there will be difficulties so that it is better prepared to deal with it because it is supported by the work experience it has can suspect there will be difficulties and be ready to deal with. (5) Work quietly, because it has a considerable sense of confidence.

Other factors that affect employee work experience are:

(1) Personal backgrounds that include education, courses, exercises, work show what was done in the past time. (2) Talent and interest in estimating one's interest and capacity or ability. (3) Attitudes and needs (attitudes and needs) to foresee one's responsibilities and authority. (4) Ability-analytical and manipulative ability to study assessment and analyzeability. (5) Teaching skills and ability, to assess job teanic ability (Handoko, 1984).

Determinants of experience as well as indicators of work experience can also use the following: (1) Duration of time / period of work, which has been taken by someone can understand the tasks - tasks of a job and have carried out well. (2). The level of knowledge and skills possessed shows knowledge of the concepts, principles, procedures, policies or other information needed by employees to understand and apply information to job responsibilities. Whereas skills refer to the physical abilities needed to achieve or carry out a task or work. (C) Mastery of work and equipment, in the implementation of technical aspects of work equipment and techniques (Foster, 2001). 
Work experience that is measured by abilities based on years of work is a determinant of one's activities and commitment to work. Experienced lecturers certainly have more in-depth knowledge and abilities towards work and lecturer positions so that it will directly influence their commitment to the organization which in this case is the university where he works as the lecturer or lecturer of the university. Therefore, differences in experience or years of work are thought to affect the commitment of a lecturer to an organization, namely the university where he works.

\section{Method}

This study uses a descriptive comparative method that is analyzing organizational commitment which is a dependent variable based on two sample groups, namely the characteristics of lecturers both gender and period of work. This study was conducted at the University of Muhammadiyah Sumatra Utara (UMSU), Jl. Captain Mukhtar Basri No. 3 Medan. The study was conducted for three months (September to November) in the 2016/2017 academic year.

The population in this study are all permanent lecturers spread across all faculties within the UMSU. With such a large population, the study uses samples with withdrawals using proportional techniques. The number of samples is determined proportionally, namely 40 male lecturers with 28 experienced and 12 less experienced; and 38 female lecturers with 25 experienced and 13 less experienced.

The study used instruments in the form of questionnaires with a Likert scale to collect data about organizational commitment. The instrument is used after fulfilling the results of the validity test and reliability test. The research design chosen was a $2 \times 2$ factorial design. $2 \times 2$ factorial design can be seen in figure 01 below.

\begin{tabular}{|l|l|l|}
\hline J.Gender/Period of Work & MK $<5$ year & MK $\geq 5$ year \\
\hline Male & & \\
\hline Female & & \\
\hline
\end{tabular}

Data analysis techniques use two-track variant analysis (two way anova) after a requirement test is normality and homogeneity (Chua, 2009; Imam Ghozali, 2005). The first hypothesis review uses an organizational commitment comparation test based on the gender of the lecturer and the second hypothesis test conducts a lecturer organizational commitment comparative test based on its working life. Whereas a third hypothesis test test tests the lecturer organization's commitment comparation as an interaction between gender and its working life. Testing is performed at a significant degree $\alpha=5 \%$.

\section{Discussion}

In the following section will be presented the results of the description of the data and its analysis including the hypothesis test and its discussion. Hypothesis tests are conducted after previously done assuming tests namely data normality and data homogenotas.Assembling test results have been performed and have met the requirements for conducting comparation tests using variant análysis. 
That is, the results of the assumption test prove that the research results data for orgnaization commitment variables have a data spread that fits the normal distribution. Whereas the results of the homogeneity assumption test prove that the data group originated is homogeneous, the Examination is outstretched at a 5\% significance rate.

The following presented descriptions of research variables obtained through data processing, namely leadership and motivation as free variables as well as organizational commitment as bound variables. Table 4.1 shows the frequency diostribute of a spread of organizational commitment data based on the sex of the lecturer and its working life. Completely the table shows that data.

Table 1 Statistics of Lecturer Organizational Commitment Data Based on Gender and Period of Work

\begin{tabular}{|l|r|r|r|r|}
\hline & $\begin{array}{c}\text { Male-P>5 } \\
\text { year }\end{array}$ & $\begin{array}{c}\text { Male-P<5 } \\
\text { year }\end{array}$ & $\begin{array}{c}\text { Female-P>5 } \\
\text { year }\end{array}$ & $\begin{array}{c}\text { Female-P<5 } \\
\text { Year }\end{array}$ \\
\hline N $\quad$ Valid & 28 & 12 & 25 & 13 \\
Missing & 12 & 28 & 15 & 27 \\
Mean & 79.89 & 78.67 & 83.08 & 63.23 \\
Median & 80.00 & 80.00 & 85.00 & 63.00 \\
Mode & 80 & 80 & 80.00 & 63.00 \\
Std. Deviation & 8.62 & 7.92 & 7.39 & 6.99 \\
\hline
\end{tabular}

a. Multiple modes exist. The smallest value is shown

Table 4.1 data shows that out of the number of male lecturer respondents as many as 40 people and women 38 people. For male lecturers with a working life of 5 know n or more have an orgnaization commitment with a mean of 79.89 whereas whose working life is less than 5 years has an organizational commitment score with a mean of 78.57. This exposes a relatively similar commitment to male lecturers based on differences in working life. However, this is not the case for female lecturers because from table 4.1 it is known that female lecturers with a working period of 5 years or more have organizational commitment with a mean of 83.08 while work periods are less than 5 years with a mean of 63.23. This shows the contractual value for female lecturers that the working period of the female lecturers' groups is very different. Henceforth, a hypothesis test will be conducted to prove three research problem formulations as proposed in the first chapter.

Table 2. Results of Analysis for Testing Research Hypotesis

Dependent Variable:Komitmen Orgns

\begin{tabular}{|l|r|r|r|r|r|}
\hline Source & $\begin{array}{c}\text { Type III Sum } \\
\text { of Squares }\end{array}$ & Df & Mean Square & \multicolumn{1}{c|}{ F } & \multicolumn{1}{c|}{ Sig. } \\
\hline Corrected Model & $3586.302^{\mathrm{a}}$ & 3 & 1195.434 & 19.250 & .000 \\
Intercept & 393887.449 & 1 & 393887.449 & $6.343 \mathrm{E} 3$ & .000 \\
$\mathrm{JK}$ & 635.808 & 1 & 635.808 & 10.238 & .002 \\
\hline
\end{tabular}




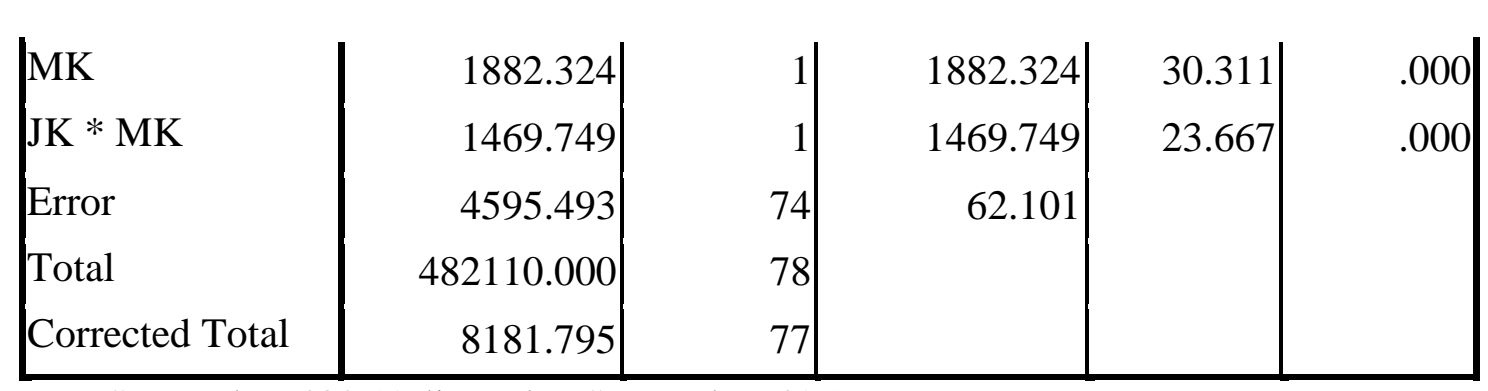

a. R Squared $=.438$ (Adjusted R Squared $=.416)$

The results of data processing on commitment of lecturer organizations based on Gender obtained that the price of $F=10,238$ while the price of significance is 0.02 which is smaller than the alpha value of 0.05 . Thus Ho is rejected and Ha is accepted. This means that the difference is significant in the sense that there are significant differences regarding lecturer organizational commitment based on gender. In this case the organizational commitment of male lecturers is higher than the organizational commitment of female lecturers. The commitment of male organizations with a mean of 79.89 while the commitment of women's organizations is with a mean of 76.28. The difference is significant at the alpha level of $5 \%$.

The results of data processing on the commitment of lecturer organizations based on gender obtained that the price of $\mathrm{F}=30.311$ while the significance price of 0.00 is smaller than the alpha value of 0.05 . Thus the difference is significant in the sense that there are significant differences regarding lecturer organizational commitment based on differences in length of service. Thus Ho rejected and Ha accepted. It means that the organizational commitment of lecturers whose working period is 5 years or more is higher than the lecturers' organizational commitment with a work period of less than 5 years. Lecturer organizational commitment with a working period of 5 years or more is with a mean of 81.40 while the organizational commitment of lecturers with work periods of less than 5 years is with a mean of 70.64. The difference is significant at the alpha level of $5 \%$.

Based on the results of data processing on the commitment of lecturer organization based on gender interaction and period of work, it was obtained that the price of $\mathrm{F}=23.67$ while the significance price was 0.00 which was smaller than the alpha value of 0.05 . Thus the difference is significant in the sense that there are significant differences regarding lecturer organizational commitment based on differences in length of service. Thus Ho is rejected and Ha is accepted. This means that the lecturers' organizational commitment is different based on the interaction between their gender and their working period. Processing data obtained mean 79.89 for male lecturer groups with a working period of 5 years or more, but $78, .67$ for male lecturers with a work period of less than 5 years, mean 833.08 for female lecturers with a 5-year work period or more and 63.23 for female lecturers working for less than 5 years. With a value of $F=23,667$ and probabliti 0,00 then Ho is rejected and $\mathrm{Ha}$ is accepted. This means that there is a difference in the comparative commitment of lecturers based on gender interaction and employment. The most effective organizing commitment is for female lecturers with a work period of less than 5 years. 


\section{Conclusion}

From the results of the analysis discussed earlier, it can be drawn in conclusion as follows:

1. There is a significant difference about the commitment of the gender-based lecturer organization that is, the commitment of the male lecturer organization (79.89) is higher compared to the commitment of the female's lecturer organization (76.28). It can thus be stated that male lecturers have a higher orgnasization commitment than female lecturers.

2. Reviewed frm period of work, there are significant differences about organizational commitment among lecturers. The commitment of a lecturer organization whose work period is 5 years or more (b1.40) is higher compared to a lecturer with a working life of less than 5 years (70.64). This means that the higher the working period the higher the commitment of the lecturer to the organization where they work.

3. Reviewed from gender intercation and work periods it concluded that there were significant differences about the commitment of the lecturer organization. The commitment of the lecturer's organization differs based on the interaction between the gender and its working life. The highest organizational commitment owner is a female lecturer who has worked 5 years or more (83.08), next is a male lecturer with a working period of less than 5 years (79.89), and third order is a female lecturer with a working life of 5 years or more (78.67) as well as the last order is a female lecturer with a working life of less than 5 years. This gives the meaning that gender is more dominant in the determination of the lecturer's orgnization commitment, and the working life will strengthen the high commitment.

\section{References}

Clark,Kenneth,E, Clark,Mary B and David P,Campbell, (1993). Impact of Leadership.Greensboro,NC : Centre for Creative Leadership.

Collquit, JA; LePine,J.A, and Wesson, M.J, (2009). Organization Behavior : Improving Performance and Commitment in the Workplace. New York:McGraw-Hill.

Chua Yan Piaw, Kaedah dan Statistik Penyelidikan (Buku 4) :Ujian Univariat dan Multivariat, Mc Graw Hill Education, (2009).

Daft, Robert, L (2005). The Leadership Experience.USA South Western : The Thomson Corp.

Durham et al, (2006).Leadership and Success in Organization, Culture and Ethics.Tulsa, Dream Point Publisher.

George,Jennifer,M and \& Jones, Gareth,R (2002), Organizational Behavio. New jersey : Prentice-Hall

Imam Ghozali. (2005). Aplikasi Analisis Multivariate Dengan Program SPSS, Edisi Ketiga, Semarang : BP-Universitas Diponegoro

Koommoo-Welch, Penny (2008). Implicit Leadership Theories: Perceptions of Charisma, People, and Performance. North Carolina : State University.

Kreitner,Robert (1995). Management.Boston: Houghton Mifflin Company

Lunenburg, F.C and Ornstein, Allan.C (2000), Educational Adminsitration : Concept and Practices, Stamford,USA: Wadsworth

Cohn.L.M,Lawrence and Morrison.K (2005). Research Methods in Education $\left(5^{\text {th }}\right.$ ed.), Taylor\& Francis. 
Luthans,Fred, (2008).Organizational Behavior, $11^{\text {th }}$ edition.Boston $:$ McGraw Hill International Edition.

McShane, Stepen, L and Mary Ann Von Glinow (2008), Organizational Behavior, fourth edition, Boston : McGraw Hill.

Mathis, Robert L dan Jhon H. Jackson.(2001). Manajemen Sumber Daya Manusia.Buku I, Translater : Jimmy Sadeli dan Bayu Prawira Hie, Jakarta : Salemba Empat.

Meyer,J.P, Allen,N.J and Gellatly,I.R, (1990). "Affective and Continuance Commitment to The Organisastion : Evaluation of Measures and ANALYSIS OF Concurrent and TimeLagged Relation" Journal of Applied Psychology.

Robbins, Stephen P. (2001). Perilaku Organisasi, Konsep, Kontroversi, Aplikasi, Alih Bahasa Hadyana Pujaatmaka dan Benyamin Molan, Jakarta: Prenhallindo.

Sopiah. (2008). Perilaku Organisasional. Edisi I, Yogyakarta : Andi Offset 